holds good if for pure we substitute loaded preminms, whether the loading be in the shape of a constant percentage, a constant addition, or a combination of the two. For in the first ease we should have

$$
\left(1+a_{x+1}\right)\left(c \pi_{x+1}-c \pi_{x}\right)<c \pi_{x z}
$$

which evidently follows from [2]. In the second

$$
\begin{aligned}
& \left(1+a_{x+1}\right)\left(\overline{\pi_{x+1}+c}-\overline{\pi_{x}+c}\right)<\overline{\pi_{x}+c}, \\
& \quad \text { or }\left(1+a_{x+1}\right)\left(\pi_{x+1}-\pi_{x}\right)<\overline{\pi_{x}+c,}
\end{aligned}
$$

which also follows evidently from [2]. And the third case is already proved, as it follows from (3) and (4) by precisely the same processes.

It appears, then, that whatever be the nature of the loading, $\pi_{x}^{\prime}>\left(1+a_{x+1}\right)\left(\pi_{n+1}^{\prime}-\pi_{x}^{\prime}\right)$, where $\pi_{x}^{\prime}$ denotes the loaded premium, follows from $\frac{1}{1+a_{x}}-(1-v)>1-\frac{1+a_{x+1}}{1+a_{x}}$; and, indeed, a little attention to the preceding process will show that the inequality is inereased by the loading. Now $\left(1+a_{x+1}\right)\left(\pi_{x+1}^{\prime}-\pi_{x}^{\prime}\right)$ is the equivalent which an Office wonld require to be paid for granting a new assurance at age $x+1$ at the rate of premium for age $x$; and as this has been shown to be less than $\pi_{x}^{\prime}$, it appears that when no extra charge is made for the option of withdrawal, the policyholder would derive an advantage by withdrawing and effeeting a new assurance in the way indicated. But if $\pi^{\prime}$ is greater than $\left(1+a_{x+1}\right)$ $\left(\pi_{x+1}^{\prime}-\pi_{x}^{\prime}\right)$, still more so is $\pi_{x}^{\prime}+e, e$ being any positive quantity. So that the imposition of an extra charge $(e)$, to cover the risk of withdrawal, merely has the effect of increasing the inducement to withdrawviz., the saving which the policy-holder would effect by availing himself of the option allowed him for the purpose of effecting a new assurance.

For convenience of illustration I have restricted the option of withdrawal to one year; but $I$ submit that my example is sufficient to show that the system-if a practical application of it should ever be attemptedwould rest on a very sandy foundation. As observed in my letter which appeared in July last, the option of withdrawal (being a contingency depending upon the will of the individual) is not a benefit susceptible of valuation, and it can be safely allowed only where the value of the policy is equal to or greater than the preminm paid-or, in other words, either where there has been no risk incurred, or where the interest on the premium paid is alone a sufficient compensation for the risk. In such cases no extra charge is necessary; but whether the option should not, in certain instances, be subject to a restriction as regards the health of the policyholder, is a question altogether foreign to the points I have touched upon.

$$
\text { I remain, Sir, }
$$

Your very obedient servant,

London, 24th May, 1860.

W. M. MAKEHAM.

\title{
ON THE TABLES OF DEFERRED ANNUITIES AS PUBLISHED BY THE GOVERNMENT.
}

\section{To the Editor.}

Drar SIR,-Since I wrote to you last year on the question of options, \&c., two letters have appeared in your Journal on the same subject; one by Mr. Makeham and the other by Mr. Younger-both writers differing 
much from me, but more from each other-the latter offering a mathematical solntion of the problem, purporting to show that " a very moderate supposition of the probability of withdrawal increases the premium more than 50 per cent.;" a problem which the former has declared to be "impossible," as the value of such policies always exceeds the premiums paid upon them. Before, however, more particularly noticing the letters of these gentlemen, I beg to submit to their serious consideration the following hypothetical case for the opinion of any actuary.

A. B., aged $x$ years, has paid the principal sum of $f 1$ to C. D., on the trusts following (that is to say): -

1st. To invest the interest on the above sum, year by year, in the assurance of an annuity to be continued during the remainder of the life of A. B. after $n$ years.

2nd. At the end of the said term of $n$ years to sink the above sum of $\mathfrak{f l}$ in the purchase of an immediate annuity payable during the life of the said $A$. B., who will then (if alive) have attained the age of $\overline{x+n}$ years.

3rd. The above trusts are subject nevertheless (as far as the principal sum is concerned) to an absolute power of revocation by the said A. B., his executors or administrators, at any time during the said term of $n$ years. Should the power of revocation be exercised, all claim to interest is abandoned.

$\mathrm{Mr} . \longrightarrow$ is requested to state what amount of annuity can be assured by the above payment of $\mathfrak{E} 1$; and further, to point ont whether the benefits secured under the above arrangement differ from those offered by the Government under their scale for assuring deferred annuities, with the return of the preminm at death, or, at the option of the purchaser, at any time before the annuity commences; and, if so, in what respect?

I submit that the inevitable answer to the above case will be-

1st. That the interest on the sum of $£ 1$ will assure a deferred annuity of $\frac{i}{p_{x_{n}}}=\frac{\left(\mathrm{N}_{x}-\mathrm{N}_{x+n}\right) i}{\mathrm{~N}_{x+n}}$.

2nd. That the principal sum of $\mathfrak{f 1}$ will, at the age of $\overline{x+n}$, purchase an immediate annuity of $\frac{1}{a_{x+n}}=\frac{D_{x+n}}{N_{n+n}}$, making together a total annuity of $\frac{i}{p_{x n}}+\frac{1}{a_{x+n}}=\frac{\left(\mathrm{N}_{x}-\mathbf{N}_{x+n}\right) i+\mathrm{D}_{x+n}}{\mathbf{N}_{x+n}}$.

3rd. That as, nnder the powers of revocation, A. B. can recall the principal sum of $\mathfrak{E 1}$ at any time during the term, and as his execntors or administrators can and will, under the same power of revocation, do so at his death, it necessarily follows that the benefits conferred ander the trast are identical with those assured under the Government scheme, bat generally at a much lower price.

This answer is the reciprocal of the formula which I gave in my first letter, which made

$$
\mathrm{P}_{x}=\frac{1}{\frac{i}{p_{x_{n}}}+\frac{1}{a_{x+n}}}=\frac{\mathrm{N}_{x+n}}{\left(\mathrm{~N}_{x}-\mathrm{N}_{x+n}\right) i+\mathrm{D}_{x+n}}
$$

But if this be not the true preminm for the assurance of the deferred 
annuity, it mast be either too high or too low; if too high there must be a profit, if too low there must be a loss.

Now, as the only element to be determined (as far as the option is concerned) in this "new and impossible problem" is the trne value of $p_{x_{n}}$, it is in this quantity alone that profit or loss can arise; and it is quite clear (a true table of mortality being assumed) that nothing can accue on this head except possible profit from the forfeiture of interest on the withdrawal of bealthy lives.

Ought this profit, contingent on the forfeiture of policies, to enter into a calculation for determining the true premium for any assurance? In my opinion, clearly not; and I should most fairly have "laid myself open" to adverse criticism, had I, when impugning the correctness of the Government tables, based my objections, even in part, on their not having taken into consideration this equivocal source of profit. But should any of your readers think otherwise, nothing is easier than to determine the value of $p_{x_{n}}$ by another table in which the decrements at each age during the term are so increased that they may accord with any theory as to the number of forfeitures or withdrawals which experience may suggest, in which case, calling the new preminm $p_{x_{n}}^{\prime}$, and substituting in the original equation, we get $\mathrm{P}_{x}=\frac{1}{\frac{i}{p_{x_{n}}^{\prime}}+\frac{1}{a_{x+n}}}$, which is an exact solution of the problem nnder these conditions, still further reducing the valne of $\mathrm{P}_{x}$, and proving that were it not that the option renders it necessary to pay everybody at the moment of claiming, there would be no pretence for charging more than the ordinary premium for return at death only.

If we apply this formula to the illustration given in Mr. Yonnger's letter, in which the age of entry is 50 , the term 10 years, the probability of withdrawal at the beginning of each year $=\cdot 05$, and the table the Carlisle 4 per cent., we shall find that $P_{x}=5 \cdot 69$, instead of 6.303 which is the true value as deduced from the original equation.

Having said thus much in support of my solution of the problem, I will now more particularly direct your attention to that offered by Mr. Yonnger, whence it appears that he has arrived at the conclusion that

$$
\mathrm{P}_{x}=\frac{\mathrm{N}_{x+n}}{(1-\mathrm{Q}) \mathrm{D}_{x}}
$$

A glance at the form of this equation at once tells us that $P_{x}$ increases as $Q$ increases, until, when $Q=1$, the denominator vanishes, and $P_{x}=\infty$. The question then arises, what is $Q$, and is unity a possible value?

Mr. Yonnger tells us that $Q$ is the "valne of the risk of death and withdrawal"; bnt as all claims are paid at the moment of death or withdrawal, it follows that $Q=1$ on the supposition that all the members die or withdraw during the first year. His formula thus shows that the premium for assuring an annuity which by hypothesis can never be entered upon, is a sum of money infinitely great. This, it is needless to say, is an extreme case, but it might easily be shown, in numerous other instances, that Mr. Younger's formula makes the valne of a deferred life annuity greater than that of an immediate perpetuity. 
One reason why such remarkable results are obtained is, that the expression $\frac{N_{x+n}}{D_{x}}$ has been introduced, which, being a function of $l_{x+a}$, is inconsistent with the value of $\mathrm{Q}$ in which $l_{x+n}$ has become $\lambda_{n}$.

Little need be said in reply to Mr. Makeham's letter, as in it he says, that if the problem had been differently stated I should not have laid myself open to the exception which he has taken.

Now, really, if in Mr. Makeham's eyes the solntion was nnexceptionable, and his objection was to the mode of stating the problem, "Why did he not say so at first?" But he has suggested that even his objection to the mode of stating the problem would have been obviated had I undertaken " to show how the assurance might be effected so as to reserve to the policy-holder the control over the premium paid, instead of proposing to * find the premium required for the assurance with the option of withdrawal."

Surely this is a distinetion without a difference. How is it possible to show how an assurance can be effected, without finding the preminm to be paid? and how can the policy-holder have the option of withdrawal without having " control over the money," and conversely?

To my mind it is always a matter of great importance to depart as little as possible from the terms in which a problem is brought before you, as by doing so a divergence of views is rendered more immediately apparent. Had I proposed it in that which I considered its simplest form, I should have done so as follows:-

What amount of deferred annuity can be secured to a person for each payment of $£ 1$, the assured reserving to himself and his representatives the "option" of withdrawing the money so paid (withont interest) at any time before the annuity commences.

In this method of treating the subject the option has a more extended signification than I had given it in my previous letter, but I have always considered this the more correct way of looking at the question, as the return of the premium at death is only a particular case of the exereise of the option of withdrawal, and it is moreover in conformity with the solution in which the deferred and immediate annuities are alone involved.

There are several other points in Mr. Makeham's letter which are open to objection, bnt to enter into these would be to depart from those broader views which onght always to be advocated in journals devoted to scientific pursuits.

In conclusion I will only add, that in introdncing the subject to your notice I had no idea of proposing a new theory of the valne of options, but simply of demonstrating that $\frac{\mathrm{N}_{x+n}}{\left(\mathrm{~N}_{x}-\mathrm{N}_{x+n}\right) \dot{i}+\mathrm{D}_{x+n}}$ was amply sufficient to secure to an assurer all the benefits proposed to be conferred under the Government tables, including the "option" of the witbdrawal of the premium paid, at any time dnring the term, either by himself or his representatives-and I have done so.

Yours truly,

London, $3 \pm t h M a y, 1866$.

J. W. STEPHENSON. 